$x$-ray examination will show typical chondrocalcinosis articularis.

1 Faires, J. S., and McCarty, D. J. Jr., Clinical Research, 1961, 9, 329. McCarty, D. J. Jr., and Hollander, J. L., Annals of Internal Medicine, $1961,54,452$

Seegmiller, J. E., Howell, R. R., and Malawista, S. E., Fournal of the American Medical Association, 1962, 180, 469.

- Popert, A. J., and Hewitt, J. V., Annals of Rheumatic Diseases, 1962, 21,

Hall, A. P., Barry, P. E., Dawber, T

Fournal of Medicine, 1967, 42, 27. Diseases, 1960, 19, 120.
.

7 Kellgren, J. H., Annals of Rheumatic Diseases, 1964, 23, 109.
K Klemperer, F., and Bauer, W., Fournal of Clinical Investigation, 1944, 23, 950 . - Yu, T-F, and Gutman, A. B., Fournal of Clinical Investigation, 1959, 38,

10 Bennett, P. H., and Wood, P. H. N., eds. Population Studies of the Rheumatic Diseases, p. 457. Proceedings of the 3rd international symposium, New York, 1966. Amsterdam, Excerpta Medical Foundation, 1968.

11 Wallace, S. L., Bernstein, D., and Diamond, H., Fournal of the American Medical Association, 1967, 199, 525.

12 Gutman, A. B., Arthritis and Rheumatism, 1965, 8, 911.

13 Hughes, G. R., Barnes, C. G., and Mason, R. M., Annals of Rheumatic Diseases, 1968, 27, 67 .

14 Scott, J. T., British Medical fournal, 1969, 3, 456.

15 Barnes, C. G., Practitioner, 1972, 208, 101.

16 Zimmerman-Gorska, I., and Koscianska, J., Annals of Clinical Research,

17 Currey, H. 95. L. F., Key, J. J., Mason, R. M., and Swettenham, K. V., Annals of Rheumatic Diseases, 1966, 25, 295.

\section{Respiratory Distress Syndrome}

Respiratory distress syndrome remains a serious disorder of newborn babies. ${ }^{12}$ About $10-15 \%$ of infants with a birth weight of $2,500 \mathrm{~g}$ or less develop it. ${ }^{3}$ Though birth by caesarean section, particularly after vaginal bleeding, and being born of a diabetic mother increase the likelihood of the syndrome, prematurity is by far the commonest condition associated with it. There is no specific treatment, and between 20 and $40 \%$ of infants with the diagnosis succumb. Even in infants of 35 weeks gestation or more the mortality is $10 \% .4$ For the obstetrician considering the timing of elective and possibly premature delivery, precise indication of the risk of the infant's developing this syndrome would clearly be of value.

The aetiology of the disorder remains obscure, but it seems to be linked with some still unrecognized prenatal disturbance or impaired development in systems for the production of fibrinolytic activators, for the control of pulmonary blood flow and capillary permeability, or for surfactant synthesis. ${ }^{2}$ E. O. R. Reynolds and colleagues ${ }^{5}$ concluded that the crucial factor in causing respiratory distress is deficiency of surfactant, a lipoprotein which reduces surface tension within the lung. This lipoprotein facilitates expansion during inspiration and prevents pulmonary collapse during expiration. Surfactant is formed in alveolar cells, ${ }^{6}$ and its main surface-active component is dipalmitoyl lecithin. ${ }^{7}$ Its increased accumulation in the alveoli towards term is mirrored in a sharply rising concentration in the amniotic fluid from the 33rd week of pregnancy. The increase in concentration is not paralleled by an increase in concentration of another surface-active phospholipid sphingomyelin, and thus it was suggested that the relative concentration of these phospholipids in amniotic fluid could provide an index of the production of pulmonary surfactant and of the likelihood of the syndrome appearing if delivery is not postponed. ${ }^{8}$
The validity of this hypothesis and its usefulness in clinical practice were supported by the work of $\mathbf{C}$. R. Whitfield and his colleagues. 9 They found the lecithin/sphingomyelin ratio to be $0.8-2.0$ up to 32 weeks gestation, with a wide range thereafter, but at least 1.5 at 38 weeks and 2.0-9.0 at term. When the ratio was determined within 48 hours of delivery it was greater than 2.0 in 102 infants who did not subsequently develop the syndrome, less than 1.5 in 10 of whom 8 did develop it, and between 1.5 and 2.0 in 16 of whom 4 were affected. They added the notable observation that in pregnancies complicated by diabetes mellitus and severe rhesus isoimmunization the expected terminal rise in the ratio did not occur, and indeed in 3 out of 10 pregnancies of diabetic women a fall in the ratio was observed.

S. G. Bhagwanani and co-workers ${ }^{10}$ found chromatographic assessment of the lecithin/sphingomyelin ratio to be difficult but that quantitation of amniotic lecithin correlated with subsequent development of the syndrome. Ninety-seven infants, including 12 of low birth weight in whom samples of amniotic fluid obtained within 24 hours of delivery had contained more than $3.5 \mathrm{mg}$ of lecithin/100 $\mathrm{ml}$, did not develop respiratory distress syndrome, while 12 infants with levels of $0 \cdot 6-3.4 \mathrm{mg} / 100 \mathrm{ml}$ and one infant with Pierre Robin syndrome and a level of $6.9 \mathrm{mg} / 100 \mathrm{ml}$ were affected.

Both of these methods require skilled technical assistance and complex and expensive equipment, and they are timeconsuming. J. A. Clements and colleagues ${ }^{11}$ now describe in detail a simple, inexpensive, rapid, semiquantitative test for surfactant in which the ability of the amniotic fluid to form a stable foam is determined in $47.5 \%$ ethanol. False positive results are obtained if the amniotic fluid is contaminated with meconium, serum of more than $7 \%$ final concentration, ascitic fluid, vaginal fluid, or dirty glassware. In a double-blind field trial 68 infants whose amniotic fluid tested 24 hours before birth gave a positive test at $1 / 2$ dilution were not affected by respiratory distress syndrome, but all whose test at $1 / 1$ dilution was negative were affected. Of 13 infants whose tests were positive at $1 / 1$ dilution and negative at $1 / 2$ eight developed the syndrome. The results correlated well with the lecithin/sphingomyelin ratio, ${ }^{8}$ and the authors concluded that the test is sufficiently reliable and informative to merit extensive clinical trial. Failure of complete correlation between the results of these tests done within 24-48 hours of birth and the baby's respiratory state may be due to the short turnover time of surfactant. ${ }^{12}$

Though amniocentesis is not without risk, further evaluation of these tests, with other estimates of fetal maturity, ${ }^{13}$ seems to be indicated when the timing of elective interruption of pregnancy is considered in such conditions as chronic placental insufficiency or assumed postmaturity when the exact duration of gestation is unknown. In the management of pregnancy in cases of maternal diabetes serial determinations of amniotic surfactant may prove helpful, for though infants dying of respiratory distress syndrome associated with maternal diabetes appear comparatively well endowed with surfactant at the time of death ${ }^{14}$ they may have been deficient earlier. The test would seem to be most useful at present in cases of severe rhesus isoimmunization, because intrauterine transfusion is a feasible alternative to delivery at 33-35 weeks, at which time the infant is at risk of developing respiratory distress syndrome.

The development of better methods for the effective inhibition of uncomplicated premature labour ${ }^{15}$ would extend the value of the test. But further study of the surfactant system and of how to influence it pharmacologically is 
essential. M. E. Avery ${ }^{2}$ has already shown in lambs that the administration of hydrocortisone induces production of surfactant. Could the epidemiological observation of a low incidence of respiratory distress syndrome in premature infants born to heroin-addicted mothers ${ }^{16}$ be a fortuitous example of such induction in man?

1 Schaffer, A. J., and Avery, M. E., in Diseases of the Newborn, 3rd edn. p. 93. Philadelphia, W. B. Saunders, 1971 .

Scopes, J., in Recent Advances in Paediatrics, ed. D. Gairdner and D. Hull, 4th edn., p. 89. London, Churchill, 1971 .

- Gairdner, D., in Recent Advances in Paediatrics, ed. D. Gairdner, 3rd edn., p. 54. London, Churchill, 1965.

Scopes, J., British fournal of Hospital Medicine, 1970, 3, 579

- Reynolds, E. O. R., Roberton, N. R. C., and Wigglesworth, J. S., Pediatrics, $1968,42,758$.

- Gandy, G., Jacobson, W., and Gairdner, D., Archives of Disease in Childhood, 1970, 45, 289.

Gluck, L., Landowne, R. A., and Kulovich, M. V., Pediatric Research, $1970,4,352$.

Gluck, L., et al., American fournal of Obstetrics and Gynaecology, 1971, 109,440 .

Whitfield, C. R., Chan, W. H., Spro

10 British

Bhagwanani, S. G., Fahmy, D., and Turnbull, A. C., Lancet, 1972, 1, 159

12 Buckingham, S., Heinemann, H. O., Sommers, S. G., and McNary, W. F., American fournal of Pathology, 1966, 48, 1027 .

13 Lind, T., and Billewicz, W. Z., British fournal of Hospital Medicine, 1971, 5,681 .

14 Boughton, K., Gandy, G., and Gairdner, D., Archives of Disease in Childhood, 1970, 45, 311 .

15 Casparis, A. W.-de, et al., British Medical fournal, 1971, 3, 144.

16 Glass, L., Rajegowda, B. K., and Evans, H. E., Lancet, 1971, 2, 685.

\section{Predicting Coronary Artery Disease}

It is becoming clear that there is no single cause of the high incidence of coronary artery disease in developed countries. The Framingham study in the U.S.A. showed that hypertension greatly increases the risk of its developing, and there is also considerable evidence that smoking cigarettes and a positive family history of arterial disease do so. In the last few years interest has risen in the elaborate analysis of plasma lipids other than cholesterol, and in younger patients especially there is some evidence that hyperlipidaemias predispose to the development of coronary artery disease. ${ }^{1-3}$ Hyperlipidaemias sometimes produce physical signs, in particular xanthelasmata, or yellowish spots in the eyelids, and may be associated with the development of a corneal arcus.

A recent study from Cambridge ${ }^{4}$ attempts to quantify the relative importance of known predisposing factors in the medical, personal, and family history of patients and in the observable physical signs in order to produce an index of discrimination between patients with and without coronary thrombosis. Approximately 100 patients with coronary thrombosis were compared with a similar number of control men of similar age whose names were obtained from the regional blood transfusion register. In each group an estimate was made of smoking and dietary habits, family history, physical characteristics, blood pressure, and plasma lipid fractions.

Diastolic blood pressure proved the best discriminator, and in decreasing order of importance were the presence of corneal arcus, degree of baldness (increased baldness being associated with coronary artery disease), presence of xanthelasmata, family history of hypertension, number of cigarettes smoked, plasma cholesterol, plasma triglycerides, and low-density lipoproteins. Statistical analyses of these characters enabled patients to be separated from controls, but the disappointing feature of it was the fact that more than half the patients fell within the range of the controls.
Thus even when all the information was taken into account its predictive value was weak. Furthermore, this discrimination was the best available from the data in this series, and it might be less on another series. Another problem in any analysis of this sort is that the controls without clinically manifest coronary artery disease may have had almost as bad disease as the patients. Further, people who volunteer to give blood are perhaps emotionally more stable than average and therefore not fully representative of the whole population. The importance of such factors as cigarette smoking, which was almost as common in controls as in patients, is difficult to evaluate by a study such as this, unless one has for comparison a group of people who have not smoked cigarettes.

But despite these reservations the investigation is useful in practical terms to a doctor called upon to advise a patient. It is of course useless to tell a patient to grow hair on his head or to remove his arcus. Nor will reducing his blood pressure prevent coronary disease, for we know from many previous studies 56 that, though hypertension predisposes to coronary artery disease, lowering the blood pressure does not reduce the chance of its developing. At best a doctor asked by a patient to assess his chances of developing coronary thrombosis can make only a rough guess. If the person concerned is muscular, obese, carries much responsibility and works long hours, smokes heavily, takes little exercise, is bald, has xanthelasmata, an arcus, a raised blood pressure, and his parents had arterial disease, he would obviously be at high risk. If his physical build, personal habits, blood pressure, and other attributes were the opposite, he would have a low risk.

If a patient with many known adverse factors were to ask for advice on preventing coronary disease, what should his doctor say? The evidence of prospective and retrospective studies indicates that the patient should keep his weight somewhat below average, eat as little as possible of known cholesterol-raising foods such as eggs, shell-fish, and animal fats, stop smoking cigarettes, and take plenty of light exercise. Frank hyperlipidaemias should be treated, where appropriate, with drugs (e.g., clofibrate). But it must be admitted that much of this advice is based on guesswork and that one could probably find world authorities to take exception to virtually every one of the recommendations. It is unfortunate that recipes for health seem to be so negative, but the results from the Cambridge study certainly underline the extent of our ignorance about the causes of occlusive arterial disease.

\footnotetext{
1 Keys, A., in Cowdrey's Arteriosclerosis, ed. H. T. Blumenthal, 2nd ed. Springfield, Thomas, 1967.

Schilling, F. J., Becker, W. H., and Christakis, G., Circulation, 1966, 33, Suppl. III, 28.

3 Rifkind, B. M., Lawson, D., and Gale, M. J., fournal of Atherosclerosis Research, 1968, 8, 167.

Cotton, S. G., Nixon, J. M., Carpenter, R. G., and Evans, D. W., British Heart fournal, 1972, 34, 458.

5 Beem, J. R., in Hypertension, ed. J. H. Moyer. Philadelphia, Saunders, 1959.

6 Hood, B., Björk, S., Sannerstedt, R., and Angervall, G., Acta Medica Scandinavica, 1963, 174, 393.
}

\section{Scrotal Cancer Continues}

The risk of scrotal cancer to metal workers who use automatic lathes was highlighted in 1968 by a case 2 in which the widow of a toolsetter who died from the disease was awarded damages of $£ 10,000$. The risk of skin cancer from 